\title{
Bursting Analysis of GFRP Composite Pipline Used in Oil \& Gas Applications
}

\author{
S. Thirumavalavan, Hariharan.R, R. Shravanan
}

\begin{abstract}
The goal of this trial study was to research the impacts of low speed effect stacking on the weight bearing limit of the E-Glass and Epoxy Composite Pipe. In this investigation we are looking at the Burst Test Results of both PVC Pipe and FRP Pipe. The examples were loaded up with water and exposed to blast test until particular spillage disappointment is watched.
\end{abstract}

Keywords : Bearing Limit, $E$ - Glass

\section{INTRODUCTION}

Elite composite segments are normally made of layers every one of them having directional properties. Composite funnels are progressively utilized in the oil and gas industry, rather than ordinary carbon steel channels. The fundamental explanation is the better erosion opposition of composite channels contrasted with steel funnels. The main composite choices to steel pipelines comprised of composite funnels dependent on thermoset frameworks[19],[21],[22]. The properties of thermoset composites are outstanding and reported. Be that as it may, the expanding requests of the oil and gas industry, including high temperature opposition and the requirement for harm resistance and adaptability, frequently surpass the abilities of thermosets. As thermoplastics can fulfill these requests, a few sorts of consistent fiber strengthened thermoplastic pipe (RTP) frameworks are at present being worked on[1],[3],[5].

Quite a bit of our current pipeline framework is built from steel. Steel is solid, precisely vigorous and generally economical. In any case, huge aggregates of cash are spent in attempting to diminish the introduction of steel pipelines to destructive situations. One approach to conquer this issue is to utilize a material with great consumption obstruction, for example, glass fiber strengthened polymers (GFRPs), rather than steel. GFRPs speak to an appealing option for pipelines exposed to serious inward or outside conditions in coastal or seaward applications[2],[4],[6].

\section{MATERIALS}

The glass fiber fabric is taken and cut into explicit measurements and with appropriate direction. The required number of layers for getting the all out thickness can be

Revised Manuscript Received on August 22, 2019.

S. Thirumavalavan, Department of Mechanical Engineering, Bharath Institute of Higher Education and Research, Chennai, Tamilnadu, India. Email: thiru_thiru@hotmail.com

Hariharan.R, Department of Mechanical Engineering, Bharath Institute of Higher Education and Research, Chennai, Tamilnadu, India. Email: mech.hariharan17@gmail.com

R. Shravanan, Department of Mechanical Engineering, Bharath Institute of Higher Education and Research, Chennai, Tamilnadu, India. Email: sharmtech@gmail.com

controlled by considering the tangle thickness and the glass-to-pitch proportion by weight.

The glass filaments are gauged and the tar is taken as 1:1 proportion by the heaviness of the fiber. At that point hardener is included by $10 \%$ of the heaviness of the tar or fiber. The gum and hardener are totally blended which structures the framework[7],[9],[11].

\section{FABRICATION OF THE GFRP COMPOSITE}

Gel coat is first applied to the shape utilizing a splash firearm for an excellent surface, which goes about as a discharging specialist among item and form.

o When the gel coat has restored adequately, move stock fiberglass support is physically put on the form.

o The covering pitch is applied by pouring, brushing, showering, or utilizing a paint roller[8],[10],[12].

o FRP rollers, paint rollers, or squeegees are utilized to merge the cover, completely wetting the support and evacuating captured air.

o Subsequent layers of fiberglass fortification are added to fabricate cover thickness.

o Setup is kept $24 \mathrm{hr}$ for relieving, after which it is evacuated cautiously.

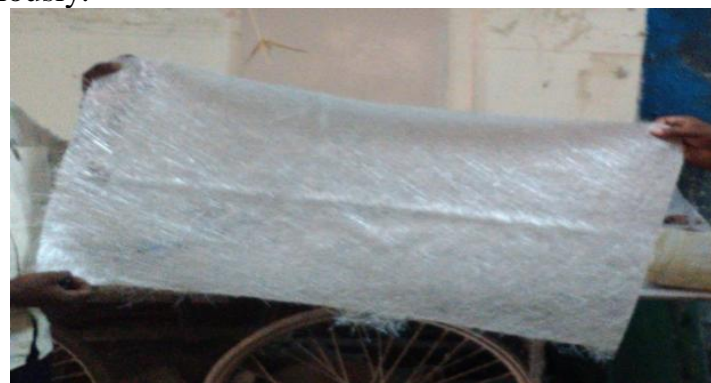

Figure - $1 \mathrm{E}-$ Glass fiber 


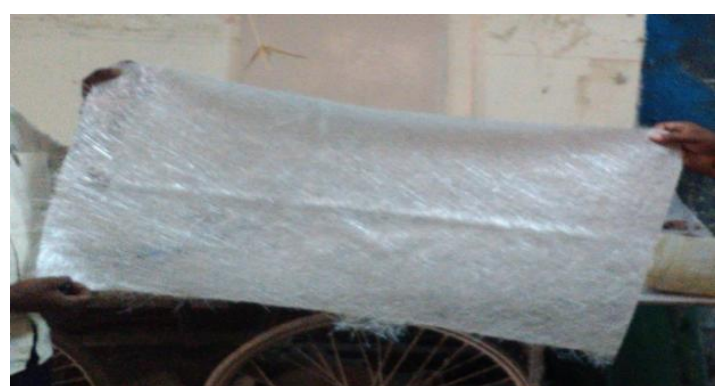

Figure 2 - Glass-Epoxy Composite (GFRP) Pipe Fabrication

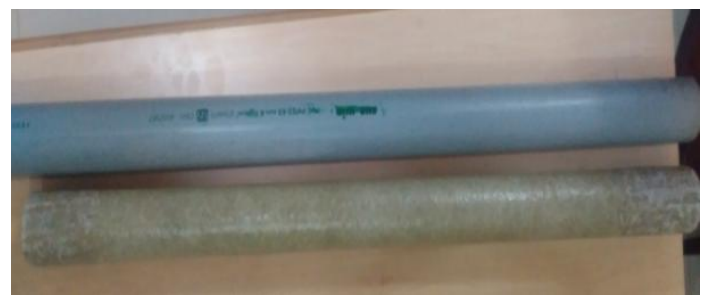

Figure - 3 PVC and GFRP Pipes

\section{TEST METHODS}

\section{A. Impact Test}

Impacttesting is ASTM standard strategy for deciding the effect obstruction of materials. An arm held at a particular tallness (steady potential vitality) is discharged. The arm hits the example.

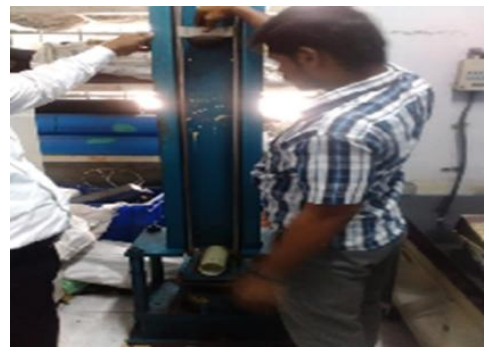

Figure - 4 Impact Test on GFRP Pipe Specimen

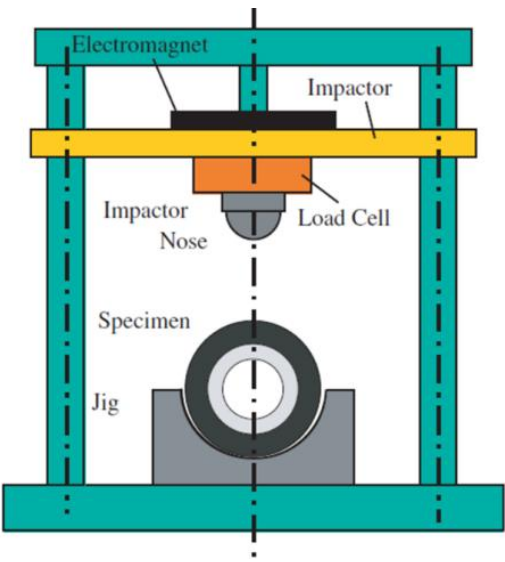

Figure 5 - Impact Tests Apparatus

\section{B. Burning Test}

The blasting quality of paper or paperboard is a composite quality property that is influenced by different properties of the sheet, chiefly elasticity and stretch[14],[16],[18]. For the most part, blasting quality relies on the sort, extent, and measure of strands present in the sheet, their strategy for readiness, their level of beating and refining, upon sheet development, and the utilization of added substances[13],[15],[17] .

The weight perusing at the moment of break is recorded as the blasting quality. The units of articulation are pounds per square inch or "points".The estimation is differently named the "Mullen", "pop test", or essentially the "burst". The burst test for paperboard contrasts from that of lighter papers in that a heavier Mullen analyzer is utilized with a bigger stomach opening

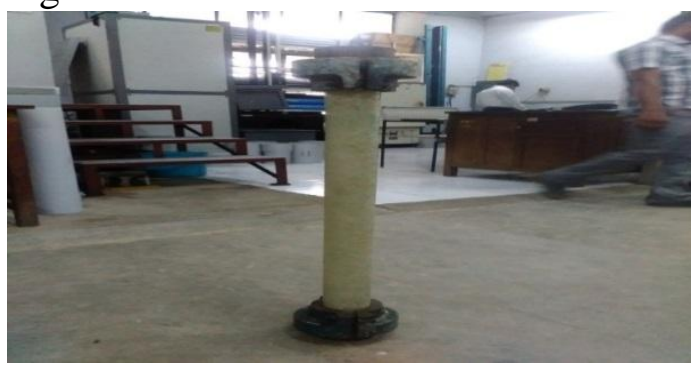

Fig.6 Fixture of GFRP Pipe Before Testing

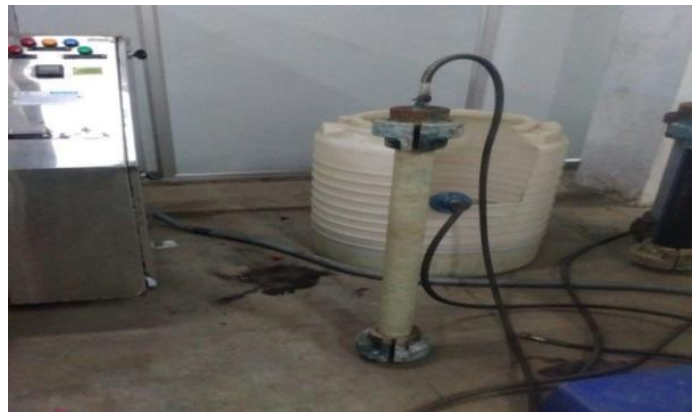

Figure 7 - GFRP Pipe Connected with Pressure Lines for

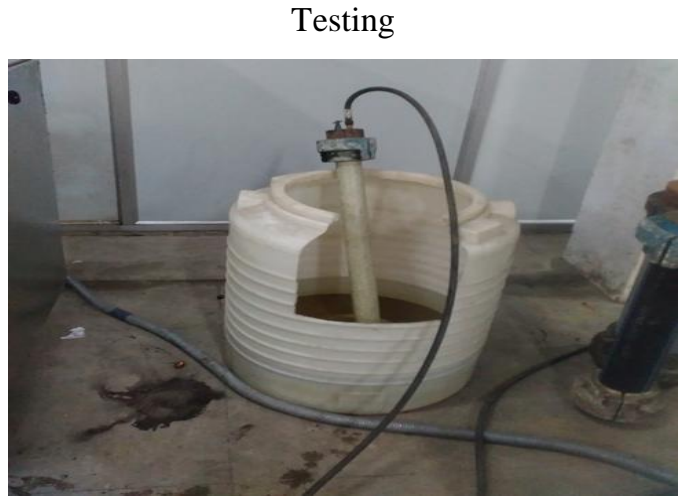

Figure - 8 Bursting Test of GFRP Pipe 


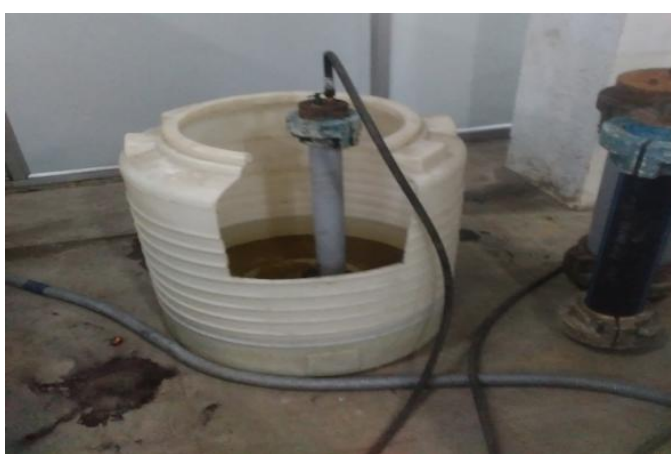

Figure 9 - Bursting Test of PVC Pipe

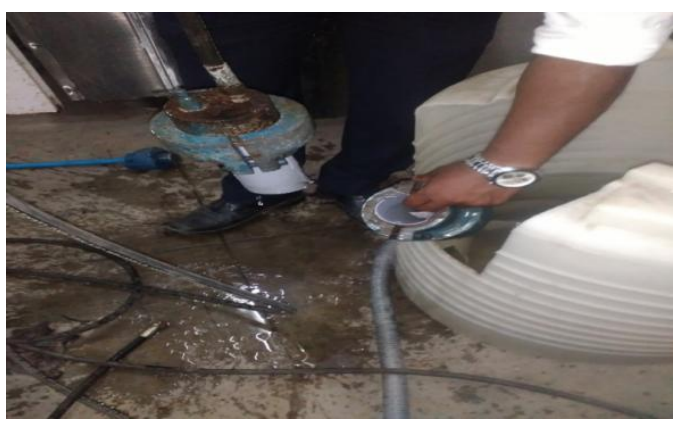

Figure 10- After Bursting Test of PVC Pipe

\section{RESULTS}

Circumference of the pipes $=63 \mathrm{~mm}$

Wall Thickness of the pipes $=2 \mathrm{~mm}$

\begin{tabular}{|c|c|c|}
\hline Sample & $\begin{array}{c}\text { Burst } \\
\text { Pressure } \\
\left(\mathrm{Kg} / \mathrm{Cm}^{2}\right)\end{array}$ & Impact Test \\
\hline UPVC Pipe & 20.0 & $\begin{array}{c}\text { No Crack } \\
\text { and Split } \\
\text { Observed }\end{array}$ \\
\hline GFRP Pipe & 34.0 & $\begin{array}{c}\text { No Crack } \\
\text { and Split } \\
\text { Observed }\end{array}$ \\
\hline
\end{tabular}

\section{CONCLUSION}

1. It is explained that the essential driver of the debasement of leftover burst quality is fiber breakage brought about by small scale clasping.

2. Delamination of glass layer likewise debases the remaining quality.

3. The burst weight limit of the pipe will diminish with increment in harm zone brought about by the effect vitality.

4. GFRP pipe of same divider thickness as PVC pipe has $70 \%$ more blasted weight limit than PVC pipe.

\section{REFERENCES}

1. Tatikonda, N.C. \& Naveenchandran, P. 2019, "The behaviour of a compression ignition engine under the influence of diesel and microalgae biodiesel blends", International Journal of Mechanical and Production Engineering Research and Development, vol. 9, no. 4, pp. 447-456.

2. Tatikonda, N.C. \& Naveenchandran, P. 2019, "An experimental assessment on the impact of injection pressure on the characteristics of a diesel engine powered with the blend of diesel and microalgae biodiesel", International Journal of Engineering and Advanced Technology, vol. 8, no. 6, pp. 3284-3291

3. Karthikeyan, S., Raman Balasubramanian, S.R., Ramesh, B., Raghul, S. \& Sathish Kumar, S. 2019, "The automatic solar tracker chronicles", International Journal of Recent Technology and Engineering, vol. 8, no. 1, pp. 312-315.

4. Hema, R., Sundararajan, M. \& Balaji, S. 2019, "Smartphone control robot with automatic firing gun", International Journal of Innovative Technology and Exploring Engineering, vol. 8, no. 9 Special Issue 3, pp. 625-627.

5. Saritha, B., Chockalingam, M.P. \& Aswathy, M. 2019, "Degradation of anionic dye using $\mathrm{Fe} / \mathrm{Tio} 2$ composite by photocatalysis", International Journal of Innovative Technology and Exploring Engineering, vol. 8, no. 9 Special Issue 3, pp. 788-791.

6. Saritha, B., Maria Subashini, L. \& Aswathy, M. 2019, "Utilization of spent coffee grounds for compost production", International Journal of Innovative Technology and Exploring Engineering, vol. 8, no. 9 Special Issue 3, pp. 908-910.

7. Fernando, J.K., Meikandaan, T.P. \& Hemapriya, M. 2019, "Better utilisation of bottom ash in coal fired thermal power station", International Journal of Innovative Technology and Exploring Engineering, vol. 8, no. 9 Special Issue 3, pp. 898-900.

8. Kumar, K.S., Kiruthiga, K. \& Thendral, S. 2019, "Experimental analysis on fractional substitution of bond by utilizing rice husk cinder", International Journal of Innovative Technology and Exploring Engineering, vol. 8, no. 9 Special Issue 3, pp. 1163-1165.

9. Vignesh, P., Madan, P., Mohankumar, D. \& Naveenchandran, P. 2019, "Optimization of four stroke c.i. engine performance by using statistical techniques (mathematical method)", International Journal of Recent Technology and Engineering, vol. 8, no. 2, pp. 1685-1691.

10. Bharanidharan, S., Sathiyamurthy, K. \& Sheeba, B. 2019, "Using co-precipitation method determining synthesis and characterization of fe doped zinc oxide nanoparticles", International Journal of Innovative Technology and Exploring Engineering, vol. 8, no. 9 Special Issue 3, pp. 705-707

11. Jeevanandan, D. \& Vino, J.A. 2019, "Heat recovery from boiler blowdown water by using heat exchanger in thermal power plant", International Journal of Mechanical and Production Engineering Research and Development, vol. 9, no. 3, pp. 219-222.

12. Rakesh, N.L., Balambica, V. \& Kannan, S. 2019, "Biogas extraction from waste orange peel by digestion process", International Journal of Mechanical and Production Engineering Research and Development, vol. 9, no. 3, pp. 323-330.

13. Meenakshi, C.M. \& Krishnamoorthy, A. 2019, "The mechanical characterization of mono and hybrid fiber reinforced composites using experimental and finite element analysis methods", International Journal of Mechanical and Production Engineering Research and Development, vol. 9, no. 3, pp. 189-196.

14. Mohankumar, D., Prem Jayakumar, M., Sabarsish, R. \& Naveen Chandran, P. 2019, "Modeling and experimental investigation on centrifugal blower by computational fluid dynamics", International Journal of Mechanical and Production Engineering Research and Development, vol. 9, no. 3, pp. 331-340.

15. Balambica, V., Deepak, V. \& Kumar, S. 2019, "Design and efficiency of an asymmetric gear", International Journal of Mechanical and Production Engineering Research and Development, vol. 9, no. 3, pp. 223-230.

16. Manavalan, S., Balakrishnan, G. \& Ramasubramaniam, S. 2019, "An effect of cobalt oxide nano additive with biodiesel blends using cidi diesel engine", International Journal of Mechanical and Production Engineering Research and Development, vol. 9, no. 3, pp. 211-218.

17. Golden Renjith Nimal, R.J., Sivakumar, M. \& Esakkimuthu, G. 2019 "An investigation on mechanical properties and microstructure of $\mathrm{mg} / \mathrm{al}$ alloys using zn interlayer during diffusion bonding", International Journal of Mechanical and Production 
Engineering Research and Development, vol. 9, no. 3, pp. 125-130.

18. Hariharan, R., Raja, R. \& Vasu, S. 2019, "Mechanical and tribological behaviour of thin tan coating produced on AISI 1018 substrate by DC magnetron sputtering", International Journal of Recent Technology and Engineering, vol. 7, no. 6, pp. 591-598

19. Manavalan, S., Rai, R., Kumar, R.R., Chaudhary, R.K. \& Chaudhary, S.K. 2019, "Impact of modified piston - A review", International Journal of Recent Technology and Engineering, vol. 8, no. 6, pp. 616-620.

20. Manavalan, S., Gopi, A., Arivarasu, J., Abishek Ahi, A. \& Chandru, S. 2019, "Review on ceramic disc brake system", International Journal of Recent Technology and Engineering, vol. 7, no. 6, pp. 612-615.

21. Sabarish, R. \& Jeya Kumar, M.P. 2019, "The design and analysis of piston - Steady state thermal analysis using "ansys"", International Journal of Mechanical and Production Engineering Research and Development, vol. 9, no. 3, pp. 197-204.

22. Ravi, D. 2019, "CFD simulation of solar loading in car", Internationa Journal of Mechanical and Production Engineering Research and Development, vol. 9, no. 3, pp. 231-236.

\section{AUTHORS PROFILE}

S. Thirumavalavan Assistant Professor, Department of Mechanical Engineering, Bharath Institute of Higher Education and Research, Chennai, India.

Hariharan.R Assistant Professor, Department of Mechanical Engineering, Bharath Institute of Higher Education and Research, Chennai, India.

R. Shravanan Assistant Professor, Department of Mechanical Engineering, Bharath Institute of Higher Education and Research, Chennai, India. 